Brit. J. prev. soc. Med. (1970), 24, 45-46

\title{
ON THE ASSERTED INVARIANCE OF THE ODDS RATIO
}

\author{
JOSEPH L. FLEISS \\ Division of Biostatistics, Columbia University
}

ONE of the most popular means for presenting evidence of the association between two characteristics is the four-fold table:

$$
\begin{array}{lll}
\text { Group 1 } & P_{1} & 1-P_{1} \\
\text { Group 2 } & P_{2} & 1-P_{2}
\end{array}
$$

The measure of association for the four-fold table most frequently employed by epidemiologists is the odds ratio (also termed the cross-product ratio and the approximate relative risk), $\omega=P_{1}\left(1-P_{2}\right) / P_{2}$ $\left(1-P_{1}\right)$. The odds ratio has been studied by Cornfield (1956) and by Mantel and Haenszel (1959).

Edwards (1966) claims a certain invariance property for the odds ratio. He asserts that if a characteristic is normally distributed with the same variance in each of two populations, then virtually any dichotomization will yield a four-fold table for which the odds ratio is relatively constant.

The Table gives values of $\omega$ for varying values of $\theta$, the difference between the two means relative to the standard deviation, and for varying dichotomization of the two populations combined. These values indicate that the asserted property of the odds ratio holds only for small values of $\theta$, with the variation in $\omega$ increasing dramatically as $\theta$ increases.

The values of two other measures of association are included in the Table for comparative purposes. One is the natural logarithm of the odds ratio, $\lambda=1 \mathrm{n} \omega ; \lambda$ has been studied by Woolf (1955) and by Haldane (1956). The other is the standardized difference between the two proportions, $\delta=\left(P_{1^{-}}\right.$ $\left.P_{2}\right) / P(1-P)$, where $P=\left(P_{1}+P_{2}\right) / 2 ; \delta$ has been studied by Yates (1955). It appears that, among the three measures presented in the Table, the standardized difference remains relatively the most invariant for fixed values of $\theta$.

Edwards (1966) asserts another property for the odds ratio, namely that it is proportional to $\theta$. In the notation of the present paper, Edwards claims that $\omega$ is approximately equal to $4 \theta / \exp (\sqrt{ } 2 \pi)$. It is seen from the Table that, whereas $\omega$ is far from being proportional to $\theta$, both $\lambda$ and $\delta$ are very nearly so, especially at a dichotomization of $50 / 50$. The constants of proportionality are effectively 1.6 for $\lambda$ and 1.56 for $\delta$.

The fact that the odds ratio is not nearly as invariant over various dichotomizations as the standardized difference, and that it is not nearly as proportional to the mean difference as its logarithm should not be taken as casting doubt on its usefulness. What is rather more important is that the epidemiologist knows what properties his selected measures of association possess, and what properties they do not possess.

\section{SUMMARY}

Two properties have been asserted for the odds ratio, approximate invariance over various dichotomizations of two overlapping, normal distributions, and approximate proportionality to the difference between the two means in units of the standard deviation. These properties are shown to be more valid for two other measures of association than for the odds ratio.

TABLE

VALUES OF THE ODDS RATIO ( $\omega$ ) THE NATURAL LOGARITHM OF THE ODDS RATIO ( $\lambda$ ), AND THE STANDARDIZED

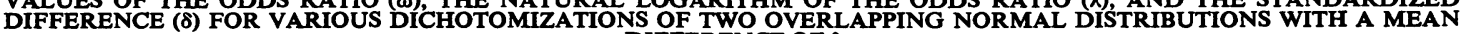

\begin{tabular}{|c|c|c|c|c|c|c|c|c|c|c|c|c|}
\hline Dichotomization & \multicolumn{3}{|c|}{$\theta=0.25$} & \multicolumn{3}{|c|}{$\theta=0.50$} & \multicolumn{3}{|c|}{$\theta=0.75$} & \multicolumn{3}{|c|}{$\theta=1.00$} \\
\hline $\begin{array}{l}50 / 50 \\
60 / 40 \\
75 / 25 \\
90 / 10 \\
95 / 5\end{array}$ & $\begin{array}{l}1.49 \\
1.50 \\
1.53 \\
1.63 \\
1.72\end{array}$ & $\begin{array}{l}0.399 \\
0.403 \\
0.424 \\
0.489 \\
0.545\end{array}$ & $\begin{array}{l}0.398 \\
0.401 \\
0 \cdot 422 \\
0.482 \\
0.534\end{array}$ & $\begin{array}{l}2 \cdot 23 \\
2 \cdot 24 \\
2 \cdot 35 \\
2.69 \\
3.02\end{array}$ & $\begin{array}{l}0.800 \\
0.808 \\
0.853 \\
0.988 \\
1 \cdot 104\end{array}$ & $\begin{array}{l}0.790 \\
0.795 \\
0.831 \\
0.933 \\
1.017\end{array}$ & $\begin{array}{l}3 \cdot 34 \\
3 \cdot 38 \\
3 \cdot 63 \\
4 \cdot 51 \\
5 \cdot 43\end{array}$ & $\begin{array}{l}1 \cdot 20 \\
1 \cdot 22 \\
1 \cdot 29 \\
1 \cdot 51 \\
1 \cdot 69\end{array}$ & $\begin{array}{l}1 \cdot 17 \\
1 \cdot 18 \\
1 \cdot 21 \\
1 \cdot 32 \\
1 \cdot 41\end{array}$ & $\begin{array}{r}5 \cdot 02 \\
5 \cdot 11 \\
5 \cdot 70 \\
7 \cdot 81 \\
10 \cdot 16\end{array}$ & $\begin{array}{l}1 \cdot 61 \\
1.63 \\
1.74 \\
2 \cdot 06 \\
2.32\end{array}$ & $\begin{array}{l}1.53 \\
1.54 \\
1.56 \\
1.64 \\
1.70\end{array}$ \\
\hline Relative range (\%) & 15 & 37 & 34 & 35 & 38 & 29 & 63 & 41 & 21 & 102 & 44 & 11 \\
\hline
\end{tabular}
DIFFERENCE OF $\theta$ 


\section{REFERENCES}

CoRNFIELD, J. (1956). A statistical problem arising from retrospective studies. J. Neyman, Ed. Proceedings of the Third Berkeley Symposium, Vol. IV. P. 135. University of California Press, Berkeley.

EDWARDS, J. H. (1966). Some taxonomic implications of a curious feature of the bivariate normal surface. Brit. J. prev. soc. Med., 20, 42.

HALDANE, J. B. S. (1956). The estimation and significance of the logarithm of a ratio of frequencies. Ann. hum. Genet., $20,309$.
MANTEL, N., and HAENSZEL, W. (1959). Statistical aspects of the analysis of data from retrospective studies of disease. J. nat. cancer Inst., 22, 719.

Woolf, B. (1955). On estimating the relation between blood group and disease. Ann. hum. Genet., 19, 251.

YATES, F. (1955). The use of transformations and maximum likelihood in the analysis of quantal ex- $\mathbb{\Phi}$ periments involving two treatments. Biometrika, 42, 382. 